\title{
Comparación de SDS-PAGE y métodos inmunoquímicos para la detección de proteínas de soja en productos cárnicos crudos y cocidos
}

\author{
Comparison of SDS-PAGE and immunochemical methods for the \\ detection of soy proteins in raw and cooked meat products
}

\begin{abstract}
The aim of this study was to evaluate the detection of soy proteins in raw and cooked meat products using SDS-PAGE and immunochemical methods. Ten raw model systems of bovine meat added with soy protein isolates, eight cooked model systems of boneless ham added with soy protein isolates and eight commercial meat products were analized. Model systems and commercial samples were analyzed by SDS-PAGE, Dot Blot, Immunoblotting and ELISA (Soy allergen kit from Neogen). Dot blot and Immunoblotting resulted to be the most sensitive analytical methods for the detection of soy proteins. The concentrations of the soy protein isolate obtained with the ELISA kit were much lower than real values. Soy proteins that were not declared in the label of several samples were detected using different methods. The heat treatment applied to the cooked meat products would affect the solubility of soy proteins and their ability to react with the antibodies of the ELISA kit used.

Key words: Soy, SDS-PAGE, blotting, ELISA, meat products.
\end{abstract}

\section{INTRODUCCIÓN}

En la elaboración de los productos cárnicos es frecuente el agregado de proteínas extrínsecas como plasma bovino o porcino, productos derivados de la soja y diferentes materias primas lácteas (caseinato, suero de queso, leche en polvo descremada, entre otras), colágeno, gelatina, entre otras (1). Estas proteínas actúan como agentes de retención de agua y emulsionantes de grasa, mejoran la liga durante el masajeo, permiten obtener muy buena coagulación durante la cocción y confieren brillo y humectación al producto terminado. Algunas de las proteínas mencionadas son alérgenos alimentarios y por lo tanto constituyen un riesgo para pacientes alérgicos, fundamentalmente cuando dichas proteínas no están declaradas en la lista de ingredientes. Según el Código Alimentario Argentino, es obligatorio declarar en el rótulo la totalidad de los ingredientes empleados (2). Sin embargo en algunos productos se pueden detectar ingredientes proteicos no declarados (3).

La alergia alimentaria es una respuesta inmunológica anormal a un alimento o a algún componente alimentario (4). La prevalencia es mayor en niños, se estima que $6-8 \%$ sufre alergias alimentarias. La mayoría de los niños superan su alergia alimentaria entre los 2 y los 6 años de edad. En adultos es menor, aproximadamente 2\% (4).

Existen ocho grupos de alimentos que son responsables
Karina Cellerino María Julieta Binaghi Carolina Elisa Cagnasso

Guillermo Docena

Laura Beatriz López

Cátedra de Bromatología, Facultad de Farmacia y Bioquímica, Universidad de Buenos Aires, Argentina.

Dirigir la correspondencia a: Profesora Karina Cellerino
Cátedra de Bromatología, Facultad de Farmacia y Bioquímica Universidad de Buenos Aires Junín 956. 2do piso. CP 1113 Buenos Aires, Argentina Tel/Fax: 54114964-8243 E-mail: karinacele@yahoo.com.ai laulop@ffyb.uba.a

Este trabajo fue recibido el 6 de Marzo de 2012 y aceptado para ser publicado el 2 de Julio de 2012.

del $90 \%$ de las alergias alimentarias, entre estos encontramos: leche, huevo, soja, trigo, maní, frutos secos, pescado y mariscos. Además se define un segundo grupo de alimentos alergénicos, ellos son los segundos grandes ocho: mostaza, sésamo, girasol, algodón, moluscos, lentejas, arvejas y amapola (5-8).

Es necesario contar con metodología que permita la detección de las proteínas alergénicas extrínsecas utilizadas para la elaboración de productos cárnicos.

El objetivo del presente trabajo fue evaluar la detección de proteínas de soja en productos cárnicos crudos y cocidos utilizando SDS-PAGE (electroforesis en gel de poliacrilamida con dodecilsulfato de sodio) y métodos inmunoquímicos (Dot Blot, Inmunoblotting y ELISA).

\section{MATERIALES Y METODOS Muestras}

Sistemas modelo. Se analizaron diez sistemas modelo crudos de mezclas de carne vacuna con agregado de aislado de soja: 0 ppm, 10 ppm, 50 ppm, 100 ppm, 250 ppm, 500 ppm, 1000 ppm, 2000 ppm, 3000 ppm, 5000 ppm de aislado de soja y ocho sistemas modelo de mezclas de fiambre de cerdo cocido con agregado de aislado de soja: 0 ppm, 10 ppm, 50 ppm, 100 ppm, 250 ppm, 500 ppm, 1000 ppm y 2000 ppm de aislado de soja.

Los sistemas modelos crudos se elaboraron mezclando 
en una trituradora carne vacuna picada comercial con aislado de soja de origen comercial en diferentes proporciones de manera de obtener las concentraciones de aislado de soja descriptas anteriormente. Para la elaboración de los sistemas modelo de fiambres de cerdo cocido se utilizó un fiambre de cerdo con $0.2 \%$ de aislado de soja y un fiambre de cerdo sin agregado de proteínas extrínsecas. Se mezclaron en trituradora ambos fiambres en diferentes proporciones de manera que cada sistema modelo tuviera las concentraciones de aislado de soja antes mencionadas. Ambos fiambres de cerdo fueron elaborados en un frigorífico de la Ciudad de Buenos Aires y recibieron un tratamiento térmico en horno industrial con inyección de vapor hasta llegar a una temperatura de aproximadamente $74^{\circ} \mathrm{C}$ en el centro de la pieza.

Productos cárnicos comerciales. Se analizaron ocho muestras comerciales, productos cocidos: mortadelas (MPA, MP), jamón cocido $(J C)$, salchicha (SPO), fiambres cocidos ( $F, F S)$ y productos secos: sopressata (SF) y chorizo $(\mathrm{CH})$. Los ingredientes proteicos declarados en cada muestra comercial se presentan en la tabla 5.

\section{Tratamiento de las muestras}

Desgrasado/deshidratado de las muestras. El desgrasado/ deshidratado de las muestras previamente molidas se realizó con acetona. Se suspendió la muestra en relación $1 / 10$ y se homogeneizó en VirTis modelo 23 a baja velocidad durante 5 minutos. Posteriormente se centrifugó a 160 g durante 20 minutos y se descartó el sobrenadante. Las muestras fueron desgrasadas con acetona dos veces.

Extracción de proteínas totales. Se utilizó buffer Tris-ClH $0,0625 \mathrm{M}$ (pH: 6,8) con $3 \%$ de SDS y $2 \%$ de $2-M E$ (solución extractiva de proteínas totales). Se pesaron $30 \mathrm{mg}$ de productos desgrasados/deshidratados con acetona y se extrajeron con $2 \mathrm{~mL}$ de solución extractiva por calentamiento en baño de agua a $100^{\circ} \mathrm{C}$ durante 5 minutos con agitación y posterior centrifugación a $500 \mathrm{~g}$ durante 15 minutos.

\section{Determinaciones analíticas}

Análisis electroforético. SDS-PAGE: Se utilizó básicamente el sistema de Laemmli (9). Se trabajó con geles de poliacrilamida en sistema discontinuo, con gel de separación (poro fino) y gel de concentración (poro grueso). El gel de separación se preparó con $10 \%$ de acrilamida en una solución 1,5 M Tris-ClH con $0,4 \%$ de SDS (pH: 8,8). El gel de concentración se preparó con $3 \%$ de acrilamida en una solución 0,5 M Tris-ClH con 0,4 $\%$ de SDS (pH: 6,8). La electroforesis se realizó con equipo Mini Protean $®$ Tetra cell de BioRad a $180 \mathrm{~V}$ durante 45 minutos. La tinción se realizó con Coomassie Brilliant Blue R 250. Las resoluciones proteicas obtenidas se densitometraron con equipo Shimadzu Dual - Wavelength Chromatogram Scanner Model CS - 910. Se trabajó con longitud de onda de máxima absorción de $550 \mathrm{~nm}$ y de mínima absorción utilizada como referencia de $400 \mathrm{~nm}$. La adquisición de datos se realizó con el programa Chromatography Station CSW de DataApex Ltd. (1).

Todas las muestras fueron analizadas por duplicado.

Métodos inmunoquímicos. Dot Blot: Se sembraron sobre la membrana $3 \mathrm{~mL}$ de cada extracto. Luego se bloqueó con 7 $\mathrm{mL}$ de solución de bloqueo (1,2 g de plasma porcino se llevan a $30 \mathrm{~mL}$ con la solución TBS-Tween 20: $125 \mathrm{~mL}$ de tween 20 se llevan a $100 \mathrm{~mL}$ con la solución TBS) y se incubó durante 30 minutos con agitación. Se agregaron 5,8 mL del Anticuerpo primario (antisuero policlonal obtenido en conejos específico de proteínas de soja) y se incubó 1 hora y 30 minutos con agitación.
Posteriormente se descartó la solución y se lavó 3 veces, durante 5 minutos cada vez, con $7 \mathrm{~mL}$ de solución TBS-Tween 20, con agitación.

Se agregaron $7 \mathrm{~mL}$ de solución de bloqueo y $15 \mathrm{~mL}$ del anticuerpo secundario (Anti IgG conjugado con fosfatasa alcalina de Bio-Rad). Se agitó 1 hora 30 minutos. Se lavó 3 veces durante 5 minutos cada vez con $7 \mathrm{~mL}$ de solución TBS-Tween 20, con agitación.

Se tiñó la membrana con $7 \mathrm{~mL}$ de reactivo colorante de Bio-rad (Catalog Number 170-6432). La misma se dejó reposar durante 7 minutos. Finalmente se lavó tres veces, durante 3 minutos cada vez, con $7 \mathrm{~mL}$ de agua destilada, con agitación (10).

Los dots fueron densitometrados por reflexión con equipo Shimadzu Dual - Wavelength Chromatogram Scanner Model CS - 910. Se trabajó con longitud de onda de máxima absorción de $550 \mathrm{~nm}$.

La adquisición de datos se realizó con el programa Chromatography Station CSW de DataApex Ltd.

En todos los casos se trabajó por duplicado.

Inmunoblotting. Se realizó la separación electroforética por SDS-PAGE como se describió previamente.

Transferencia. Se hidrataron los geles, los filtros, las membranas previamente cortadas y los pads, con el buffer de transferencia (25 mM Tris, $192 \mathrm{mM}$ Glicina, 20\% v/v metanol, $\mathrm{pH} 8,3$ ) durante 20 minutos.

Posteriormente se preparó el sándwich de gel en el casete, el cual se colocó en el módulo de transferencia. Este módulo se colocó junto con una unidad de frío en la cuba, Ilenando la misma con buffer de transferencia. Se realizó la transferencia durante 60 minutos a 100 V y 350 mA, con agitación.

Revelado. Se realizó siguiendo el procedimiento para el revelado de Dot Blot (10). En todos los casos se trabajó por duplicado.

ELISA. La determinación por el método ELISA de la presencia de proteínas alergénicas de soja se realizó con el kit Veratox para alérgenos de soja de Neogen. Todas las muestras se analizaron por duplicado siguiendo el protocolo de trabajo del kit (11). El límite de cuantificación del presente kit es 10 ppm de aislado de soja y el rango de cuantificación es 10 - 100 ppm de aislado de soja.

\section{RESULTADOS Y DISCUSIÓN}

Sistemas modelo crudos: Carne vacuna/aislado de soja.

En la tabla 1 se resumen los resultados obtenidos en el análisis de los sistemas modelo de carne vacuna con agregado desde 0 hasta 5000 ppm de aislado de soja (SO-S9) analizados por SDS-PAGE, Inmunoblotting y Dot Blot.

En la figura 1 se presenta la resolución electroforética de proteínas de soja separadas por SDS-PAGE. Las bandas proteicas que pueden identificarse en mezcla con carne vacuna son las bandas Sa y Sb cuyos pesos moleculares son 68500 y $67000 \mathrm{D}$, respectivamente. El resto de las bandas de soja se superponen con bandas de la carne vacuna y no se observan en concentraciones tan bajas de soja $(1,10)$. En esta figura se presentan los densitogramas correspondientes a carne vacuna y los sistema modelo de mezclas de carne vacuna cruda con 50, 1000, 2000, 3000 y 5000 ppm de aislado de soja. Es posible detectar la presencia de 2000 ppm de aislado de soja en mezcla con carne vacuna. En los densitogramas correspondientes se señalan los picos Sa y Sb (sistemas modelos de carne vacuna con 2000, 3000 y 5000 ppm de aislado de soja, respectivamente).

Dot Blot e Inmunoblotting resultan mucho más sensibles 
ya que permiten la detección de 100 ppm de aislado de soja en mezcla con carne vacuna. En el inmunoblotting también se observan las bandas Sa y Sb en los sistemas modelo de carne vacuna con agregado desde 100 ppm de aislado de soja (resultados no mostrados).

En la tabla 2 se presentan los resultados obtenidos en la determinación de proteínas alergénicas de soja utilizando ELI-
SA en Sistemas modelo de carne vacuna con 0- 5000 ppm de aislado de soja. Se observó que en los sistemas modelo crudos la metodología ELISA detecta proteínas de soja a partir del sistema modelo de 250 ppm de aislado de soja. Los sistemas modelo de 250 y 500 ppm dan valores positivos y cuantificables de soja, aunque muy alejados de los valores reales. El resto de los sistemas modelo (entre 1000 y 5000 ppm de aislado de

TABLA 1

Detección de proteínas de soja en sistemas modelo de carne vacuna con 0- 5000 ppm de aislado de soja analizados por medio de SDS-PAGE, Inmunoblotting y Dot Blot.

\begin{tabular}{lcccccccccc}
\hline Sistema & SO & $\mathrm{S} 1$ & $\mathrm{~S} 2$ & $\mathrm{S3}$ & $\mathrm{S} 4$ & $\mathrm{~S} 5$ & $\mathrm{~S} 6$ & $\mathrm{~S} 7$ & $\mathrm{~S} 8$ & $\mathrm{~S} 9$ \\
Modelo & $\mathrm{O}$ & 10 & 50 & 100 & 250 & 500 & 1000 & 2000 & 3000 & 5000 \\
& $\mathrm{ppm}$ & $\mathrm{ppm}$ & $\mathrm{ppm}$ & $\mathrm{ppm}$ & $\mathrm{ppm}$ & $\mathrm{ppm}$ & $\mathrm{ppm}$ & $\mathrm{ppm}$ & $\mathrm{ppm}$ & $\mathrm{ppm}$ \\
SDS-PAGE & $\mathrm{NO}$ & $\mathrm{NO}$ & $\mathrm{NO}$ & $\mathrm{NO}$ & $\mathrm{NO}$ & $\mathrm{NO}$ & $\mathrm{NO}$ & $\mathrm{SI}$ & $\mathrm{SI}$ & $\mathrm{SI}$ \\
Inmunoblotting & $\mathrm{NO}$ & $\mathrm{NO}$ & $\mathrm{NO}$ & $\mathrm{SI}$ & $\mathrm{SI}$ & $\mathrm{SI}$ & $\mathrm{SI}$ & $\mathrm{SI}$ & $\mathrm{SI}$ & $\mathrm{SI}$ \\
Dot Blot * & $\mathrm{NO}$ & $\mathrm{NO}$ & $\mathrm{NO}$ & $\mathrm{SI}$ & $\mathrm{SI}$ & $\mathrm{SI}$ & $\mathrm{SI}$ & $\mathrm{SI}$ & $\mathrm{SI}$ & $\mathrm{SI}$ \\
& Área: & Área: & Área: & Área: & Área: & Área: & Área: & Área: & Área: & Área: \\
& 11 & 11 & 12 & 16 & 18 & 20 & 25 & 31 & 72 & 80 \\
\hline
\end{tabular}

* Los dots de los sistemas modelo se densitometraron por duplicado obteniendo las áreas de cada uno. Se calculó el promedio de las dos áreas obtenidas. Se consideró como punto de corte el valor de área que presentaba diferencia significativa del área del sistema modelo de carne vacuna sola (S0).

Los sistemas con valores de áreas superiores al valor de corte (Área: 16) se consideraron positivos.

\section{FIGURA 1}

Densitogramas correspondientes a proteínas totales de los sistemas modelo de carne vacuna con agregado de diferentes concentraciones de aislado de soja, separadas por SDS-PAGE.

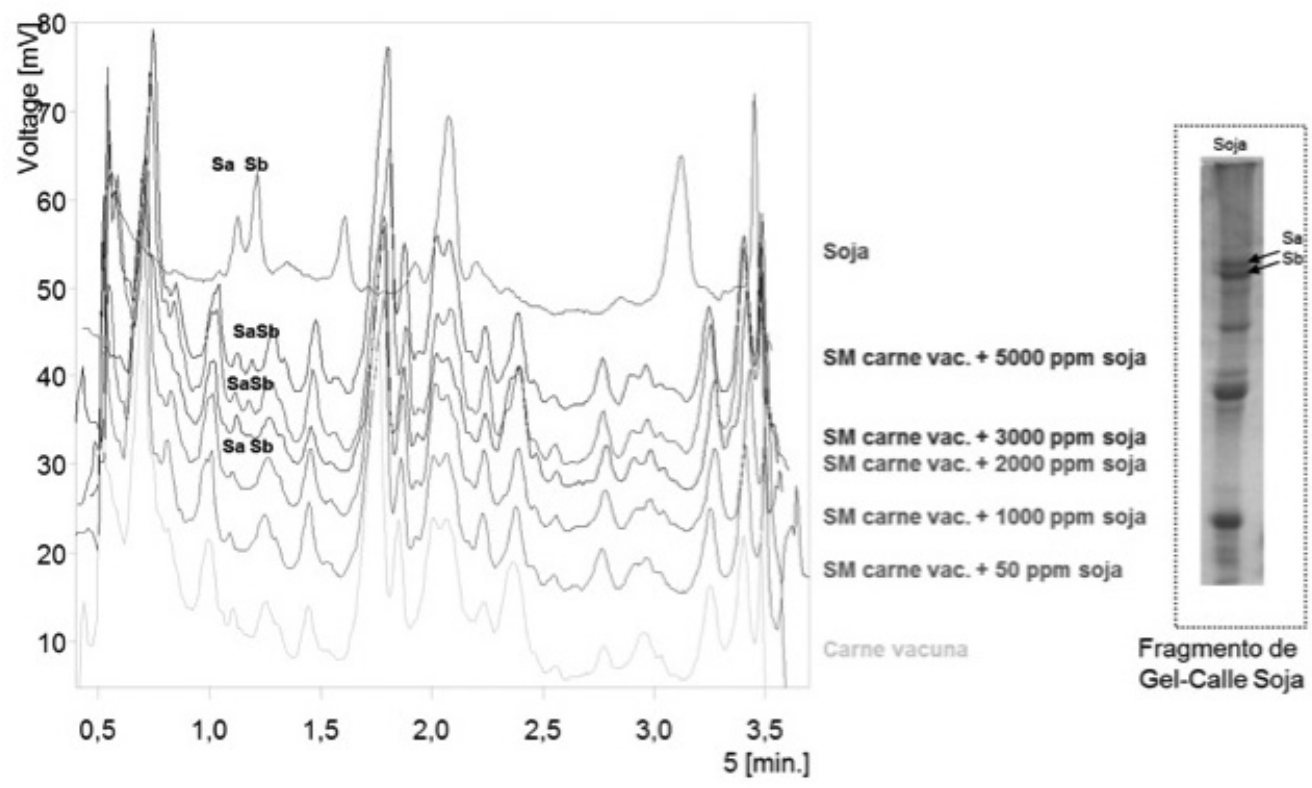

Resolución electroforética de proteínas de aislado de soja separadas por SDS-PAGE. Sa y Sb: picos de 68500 y 67000D, característicos de proteínas de soja. 
soja) presentan valores que superan el control superior de la curva de calibración (100 ppm de aislado de soja).

Sistemas modelo cocidos:

fiambre de cerdo/aislado de soja

En la tabla 3 se resumen los resultados obtenidos en el análisis de los sistemas modelo de fiambre con agregado desde 0 hasta 2000 ppm de aislado de soja analizados por SDS-PAGE, Inmunoblotting y Dot Blot.

De acuerdo con estos resultados SDS-PAGE permite la detección de 2000 ppm de aislado de soja en mezcla con fiambre mientras que Dot Blot e Inmunoblotting resultan mucho más sensibles ya que permiten la detección de 100 ppm de aislado de soja en mezcla con fiambre.

En la tabla 4 se presentan los resultados obtenidos en la determinación de proteínas alergénicas de soja utilizando ELISA en Sistemas modelo de fiambre de cerdo con 0- 2000 ppm de aislado de soja. Se observó que la metodología ELISA detecta soja a partir del sistema modelo de 250 ppm de aislado de soja. Los sistemas modelo de 250, 500 y 1000 dan valores positivos y cuantificables de soja, aunque muy alejados de los valores reales. El sistema modelo de 2000 ppm presenta un valor que supera el control superior de la curva de calibración (100 ppm de aislado de soja).

Se ve diferencia de concentraciones de proteína de soja entre sistemas modelo crudos y cocidos, en los sistemas modelo crudos la concentración de soja resulta mayor que en el sistema modelo cocido. Esto confirmaría que el tratamiento térmico aplicado en los productos cocidos afectaría la solubilidad de las proteínas de soja y su capacidad para reaccionar con los anticuerpos presentes en el kit de ELISA utilizado (12 y 13).

Productos cárnicos comerciales

En la tabla 5 se presentan los resultados obtenidos por SDS-PAGE, Dot Blot, Inmunoblotting y ELISA de las ocho muestras comerciales analizadas. Se observó que utilizando SDS-PAGE se detectó soja en las muestras FS y SPO. La muestra FS declaraba soja en su lista de ingredientes y la muestra SPO no declaraba dicha materia prima en su lista de ingredientes.

De las muestras que no declaraban soja Dot Blot detectó esta materia prima en tres muestras (SF, MPA, SPO) mientras que Inmunoblotting la detectó en cuatro de las muestras analizadas ( $F, S F, M P A, S P O)$.

Además se observó que con el método ELISA el alérgeno

TABLA 2

Resultados obtenidos en la determinación de proteínas alergénicas de soja utilizando ELISA en sistemas modelo de carne vacuna con 0- 5000 ppm de aislado de soja.

\begin{tabular}{cc}
\hline $\begin{array}{c}\text { Sistema modelo } \\
\text { ppm aislado de soja }\end{array}$ & $\begin{array}{c}\text { ELISA } \\
\text { ppm aislado de soja }\end{array}$ \\
0 & $<10$ \\
10 & $<10$ \\
50 & $<10$ \\
100 & $<10$ \\
250 & 21,6 \\
500 & 87,0 \\
1000 & $>100$ \\
2000 & $>100$ \\
3000 & $>100$ \\
5000 & $>100$ \\
\hline
\end{tabular}

TABLA 3

Detección de proteínas de soja en sistemas modelo de fiambre con 0 - 2000 ppm de aislado de soja analizados por medio de SDS-PAGE, Inmunoblotting y Dot Blot.

\begin{tabular}{|c|c|c|c|c|c|c|c|c|}
\hline Sistema & SO & S1 & S2 & S3 & S4 & S5 & S6 & S7 \\
\hline \multirow{2}{*}{ Modelo } & 0 & 10 & 50 & 100 & 250 & 500 & 1000 & 2000 \\
\hline & ppm & ppm & ppm & ppm & ppm & ppm & ppm & ppm \\
\hline SDS-PAGE & NO & $\mathrm{NO}$ & NO & NO & NO & $\mathrm{NO}$ & $\mathrm{NO}$ & SI \\
\hline Inmunoblotting & NO & NO & NO & $\mathrm{SI}$ & $\mathrm{SI}$ & $\mathrm{SI}$ & $\mathrm{SI}$ & SI \\
\hline Dot Blot * & $\begin{array}{c}\text { NO } \\
\text { Área: } \\
3\end{array}$ & $\begin{array}{c}\text { NO } \\
\text { Área: } \\
2\end{array}$ & $\begin{array}{c}\text { NO } \\
\text { Área: } \\
3\end{array}$ & $\begin{array}{c}\text { SI } \\
\text { Área: } \\
8\end{array}$ & $\begin{array}{c}\text { SI } \\
\text { Área: } \\
9\end{array}$ & $\begin{array}{c}\text { SI } \\
\text { Área: } \\
9\end{array}$ & $\begin{array}{c}\text { SI } \\
\text { Área: } \\
10\end{array}$ & $\begin{array}{c}\text { SI } \\
\text { Área: } \\
10\end{array}$ \\
\hline
\end{tabular}

* Los dots de los sistemas modelo se densitometraron por duplicado obteniendo las áreas de cada uno. Se calculó el promedio de las dos áreas obtenidas.

Se consideró como punto de corte el valor de área que presentaba diferencia significativa del área del sistema modelo de carne vacuna sola (SO).

Los sistemas con valores de áreas superiores al valor de corte (Área: 8) se consideraron positivos. 
soja fue detectado en cuatro de las muestras analizadas que no declaraban este ingrediente (F, SF, MPA, SPO). Estos resultados confirmaron los resultados obtenidos por Inmunoblotting.

En el resto de las muestras analizadas no se detectaron proteínas de soja con ninguna de las metodologías utilizadas.

La muestra F dio resultado positivo para Inmunoblotting y el método de ELISA detectó 22,3 ppm de aislado de soja. Debido a estos resultados se consultó al fabricante sobre la posibilidad de que esta muestra tuviera en su formulación algún ingrediente o aditivo que contuviera proteínas de soja.
La respuesta fue positiva ya que la muestra era elaborada con un aditivo sabor jamón que declaraba la presencia de alérgenos de soja en su composición.

En la muestra MP que declaraba aislado de soja en su lista de ingredientes no se detectaron estas proteínas con ninguna de las metodologías utilizadas. Con este resultado se confirma que no se utilizó una materia prima con soja en la elaboración de este producto. Es posible que algunas muestras presenten en su lista de ingredientes materias primas que no se encuentran en su composición. Esto podría deberse a cambios en la

TABLA 4

Resultados obtenidos en la determinación de proteínas alergénicas de soja utilizando ELISA en sistemas modelo de fiambre de cerdo con 0 - 2000 ppm de aislado de soja.

\begin{tabular}{cc}
\hline $\begin{array}{c}\text { Sistema modelo } \\
\text { ppm aislado de soja }\end{array}$ & $\begin{array}{c}\text { ELISA } \\
\text { ppm aislado de soja }\end{array}$ \\
0 & $<10$ \\
10 & $<10$ \\
50 & $<10$ \\
100 & $<10$ \\
250 & 13,3 \\
500 & 53,0 \\
1000 & 70,0 \\
2000 & $>100$ \\
\hline
\end{tabular}

TABLA 5

Resultados obtenidos en la determinación de proteínas alergénicas de soja utilizando SDS-PAGE,

Dot Blot, Inmunoblotting y ELISA en las ocho muestras comerciales analizadas.

\begin{tabular}{|c|c|c|c|c|c|c|}
\hline Muestras & Denominación & $\begin{array}{l}\text { Ingredientes } \\
\text { Proteicos Declarados }\end{array}$ & Sds-Page & Dot Blot* & Inmunoblotting & $\begin{array}{c}\text { Elisa } \\
\text { Ppm Aislado De Soja }\end{array}$ \\
\hline $\mathrm{F}$ & Fiambre de cerdo & $\begin{array}{l}\text { Carne de cerdo, colágeno } \\
\text { y gelatina hidrolizada }\end{array}$ & Negativo & $\begin{array}{l}\text { Positivo } \\
\text { Área: } 8\end{array}$ & Positivo & 22,3 \\
\hline FS & Fiambre de cerdo & $\begin{array}{c}\text { Carne de cerdo, colágeno, } \\
\text { gelatina hidrolizada } \\
\text { y aislado de soja }\end{array}$ & Positivo & $\begin{array}{l}\text { Positivo } \\
\text { Área: } 10\end{array}$ & Positivo & $>100$ \\
\hline SF & Sopressata & $\begin{array}{l}\text { Carne vacuna, } \\
\text { gluten de trigo }\end{array}$ & Negativo & $\begin{array}{l}\text { Positivo } \\
\text { Área: } 11\end{array}$ & Positivo & 67,4 \\
\hline$J C$ & Jamón Cocido & Pernil de cerdo & Negativo & $\begin{array}{l}\text { Negativo } \\
\text { Área:3 }\end{array}$ & Negativo & $<10$ \\
\hline MPA & Mortadela & $\begin{array}{l}\text { Carne vacuna, } \\
\text { carne de cerdo, almidón }\end{array}$ & Negativo & $\begin{array}{l}\text { Positivo } \\
\text { Área: } 9\end{array}$ & Positivo & 60,0 \\
\hline SPO & $\begin{array}{c}\text { Salchichas cocidas } \\
\text { de pollo }\end{array}$ & $\begin{array}{l}\text { Carne de pollo, } \\
\text { almidón. }\end{array}$ & Positivo & $\begin{array}{l}\text { Positivo } \\
\text { Área: } 9\end{array}$ & Positivo & 67,8 \\
\hline$M P$ & Mortadela & $\begin{array}{l}\text { Carne vacuna, porcina, } \\
\text { almidón, aislado de soja }\end{array}$ & Negativo & $\begin{array}{l}\text { Negativo } \\
\text { Área:3 }\end{array}$ & Negativo & $<10$ \\
\hline $\mathrm{CH}$ & Chorizo & $\begin{array}{l}\text { Carne vacuna, } \\
\text { carne de cerdo }\end{array}$ & Negativo & $\begin{array}{l}\text { Negativo } \\
\text { Área: } 3\end{array}$ & Negativo & $<10$ \\
\hline
\end{tabular}

* Los dots de los sistemas modelo se densitometraron por duplicado obteniendo las áreas de cada uno. Se calculó el promedio de las dos áreas obtenidas.

Se consideró como punto de corte el valor de área que presentaba diferencia significativa del área del sistema modelo de carne vacuna sola (SO).

Los sistemas con valores de áreas superiores al valor de corte (Área: 8) se consideraron positivos. 
formulación que no se ven reflejados en los rótulos ya que los mismos quedan desactualizados.

Los valores bajos de soja obtenidos por ELISA corroboraron los resultados obtenidos en los sistemas modelo. Si bien este método permitió la detección de soja en cuatro muestras comerciales los valores obtenidos difieren de los valores reales presentes en dichas muestras lo que se concluye ya que el límite de detección del método SDS-PAGE es 2000 ppm y el de Inmunoblotting y Dot Blot es 100 ppm. Si por ejemplo la muestra F tuviera realmente 22,3 ppm de aislado de soja el Inmunoblotting no hubiera dado positivo. Si la muestra SPO tuviera $67,8 \mathrm{ppm}$ de aislado de soja no hubieran dado positivos SDS-PAGE, Dot Blot e Inmunoblotting.

Estos resultados confirman que el método de ELISA utilizado no permite obtener concentraciones confiables de aislado de soja.

\section{CONCLUSIONES}

Dot Blot e Inmunoblotting detectan proteína de soja a partir de 100 ppm de aislado de soja, SDS-PAGE detecta a partir de 2000 ppm de aislado de soja y el ELISA soja de Neogen detecta proteínas de soja a partir de 250 ppm de aislado de soja en sistemas modelo crudos y cocidos. Los resultados hallados con Dot Blot e Inmunoblotting en Sistemas Modelo ya sean crudos como cocidos, permiten observar que la sensibilidad de estos dos métodos sería mayor que el SDS-PAGE y el ELISA soja de Neogen. Utilizando el método de ELISA soja de Neogen en los sistemas modelo de 500, 1000 y 2000 ppm se observaron valores cuantificables de soja, aunque muy alejados de los valores reales. Se observó diferencia de concentraciones de proteína de soja entre sistemas modelo crudos y cocidos, en los sistemas modelo crudos la concentración de soja resultante fue mayor que en los sistemas modelo cocidos. Esto confirmaría que el tratamiento térmico aplicado en los productos cocidos afectaría la solubilidad de las proteínas de soja y su capacidad para reaccionar con los anticuerpos presentes en el kit de ELISA utilizado.

De acuerdo con los resultados obtenidos en las muestras comerciales fue posible detectar la presencia de soja en varias muestras que no declaraban esta materia prima proteica. Si bien, según el Código Alimentario Argentino, es obligatorio declarar en el rótulo la totalidad de los ingredientes empleados, en algunos productos se pueden detectar ingredientes proteicos no declarados. Cuando tales ingredientes proteicos constituyen alérgenos alimentarios, ello puede constituir un riesgo para personas alérgicas. Por lo tanto, se debería asegurar la declaración de todos los alérgenos presentes en un alimento.

\section{RESUMEN}

Se evaluó la detección de proteínas de soja en productos cárnicos crudos y cocidos utilizando SDS-PAGE y métodos inmunoquímicos. Se analizaron diez sistemas modelo de mezclas de carne vacuna con agregado de aislado de soja, ocho sistemas modelo de fiambres de cerdo con agregado de aislado de soja y ocho muestras comerciales. Los sistemas modelo y las muestras fueron analizadas por SDS-PAGE, Dot blot, Inmunoblotting y ELISA soja de Neogen. Dot Blot e Inmunoblotting resultaron los métodos más sensibles para la detección de proteínas de soja. Con el método de ELISA se obtuvieron valores de concentraciones de aislado de soja muy inferiores a los valores reales. En varias muestras comerciales se detectaron con los distintos métodos proteínas de soja no declaradas en los respectivos rótulos. El tratamiento térmico aplicado en los productos cocidos afectaría la solubilidad de las proteínas de soja y su capacidad para reaccionar con los anticuerpos presentes en el kit de ELISA utilizado.

Palabras clave: Soja; SDS-PAGE; blotting; ELISA; productos cárnicos.

\section{BIBLIOGRAFIA}

1. López $L B$, Greco $C B$, Ronayne de Ferrer $P$ y Valencia $M E$. Identificación de proteínas extrínsecas en jamones cocidos por SDS-PAGE: nivel de detección en sistemas modelo. Arch Latinoam Nutr 2006; 56 (3): 282- 7.

2. Código Alimentario Argentino, actualizado, 2012. Disponible en: http://www.anmat.gov.ar/alimentos/codigoa/ Capitulo_V.pdf, visitada febrero 2012

3. López Laura B, Binaghi María J, Greco Carola B, Mambrín María C. Cellerino K. y Valencia Mirta E. Salazones y chacinados embutidos secos: detección por electroforesis de especies cárnicas y de proteínas extrínsecas agregadas, DIAETA 2010; 28 (131): 7-13.

4. Taylor, S. The nature of food allergy. In Koppelman Stef J., Hefle Sue L.,editors. Detecting allergens in food. Abington, Cambridge. Woodhead Publishing Limited, CB1 6AH. England, 2006. p. 3-17.

5. Hideaki T., Masumi K., Yasuo. N. Allergens in major crops, Nutr Res 2001; 21: 925-34.

6. Lehrer $S B$, Ayuso $R$, and Reese $G$. Current Understanding of Food Allergens, Ann N Y Acad Sci 2002; 964: 69-85.

7. Poms R., Klein C. and Anklam E. Methods for allergen analysis in food: a review. Food Additives Contaminants, 2004; 21 (1): 1-31.

8. Popping B, Díaz-Amigo C, Hoenicke K., editors. Molecular Biological and Inmunological Techniques and Applications for food Chemists. 1st ed. New Jersey. John Wiley \& Sons, 2010.

9. Laemmli U.K. "Cleavage of structural proteins during the assembly of the head bacteriophage t4". Nature 1970; 227: $680-5$.

10. Cellerino K. Metodología de control para el análisis de proteínas alergénicas de soja y de leche en productos cárnicos. [Tesis de maestría]. MITA - Maestría Internacional en Tecnología de los Alimentos- Facultad de Agronomía de la Universidad de Buenos Aires (FAUBA) y la Università degli Studi di Parma-Italia- Junio 2011.

11. ELISA Veratox for soy allergen (Código: 8410). Neogen. 2012. Disponible en: http://www.neogen.com/FoodSafety/pdf/ProdInfo/Page_V-Soy.pd) visitada Enero 2012.

12. Besler M., Steinhart H., Paschke A.Stability of food allergens and allergenicity of processed food. Journal of cromatography B: Biomed Sci Aplicattions. 2001; 756 (1-2): 207-28.

13. Poms R. and Anklam E., Effects of chemichal, physical and technological processes on the nature of food allergens. I AOAC Internat 2004; 87 (6):1466-74. 